\title{
Enfermeiro frente ao meio ambiente e aos trabalhadores rurais expostos aos
}

\section{agrotóxicos}

\author{
Nurses facing the environment and rural workers exposed to pesticides \\ Las enfermeras frente al medio ambiente y los trabajadores rurales expuestos a los plaguicidas
}

Recebido: 30/09/2021 | Revisado: 06/10/2021 | Aceito: 13/10/2021 | Publicado: 16/10/2021

\author{
Grasiela Maria Simão Silvino ${ }^{1}$ \\ ORCID: https://orcid.org/0000-0002-2256-9957 \\ Secretaria de Estado da Saúde de Santa Catarina, Brasil \\ E-mail: grasi_fabio@hotmail.com \\ Juliana Berns ${ }^{2}$ \\ ORCID: https://orcid.org/0000-0003-4569-4598 \\ Faculdade Estácio de Sá, Brasil \\ E-mail: juliana_berns15@hotmail.com \\ Maria Catarina da Rosa ${ }^{3}$ \\ ORCID: https://orcid.org/0000-0003-0702-1640 \\ Secretaria de Estado da Saúde de Santa Catarina, Brasil \\ E-mail: mcatarinarosa@gmail.com
}

\begin{abstract}
Resumo
O objetivo é identificar a atuação do enfermeiro frente aos trabalhadores rurais e o meio ambiente exposto aos agrotóxicos entre 2010 e 2020. Trata-se de pesquisa qualitativa, de revisão integrativa em 13 artigos encontrados em bases de dados selecionadas. Foram 13 artigos que atendiam aos critérios de inclusão. Os resultados apontam que os agroquímicos em pequena ou moderada quantidade contaminam solo, água e seres vivos, causa infecção que devem ser notificadas pelo profissional da saúde ao SINAN, oferece a Vigilância em Saúde subsídios para o cuidado ao meio ambiente. O enfermeiro ao compreender a relação entre o trabalhador rural, o meio ambiente e os agrotóxicos, permite-se visitar o objeto socioambiental, interagindo com o trabalhador (sujeito), o meio ambiente (espaço de trabalho) e os agrotóxicos (ferramenta de trabalho). Concluímos que o enfermeiro é fundamental em todas as áreas da saúde que vivenciam o atendimento do trabalhador rural e sua família, principalmente na promoção e prevenção de agravos causados pelo uso dos agroquímicos.
\end{abstract}

Palavras-chave: Enfermeiro; Agrotóxico; Meio ambiente; Trabalhador rural.

\begin{abstract}
The objective is to identify the role of nurses facing rural workers and the environment exposed to pesticides between 2010 and 2020. This is a qualitative research of integrative review in 13 articles found in selected databases. There were 13 articles that met the inclusion criteria. The results indicate that the agrochemicals in small or moderate amounts contaminate soil, water and living beings, causing infection that must be notified by health professionals to SINAN, offers the Health Surveillance subsidies to care for the environment. By understanding the relationship between rural workers, the environment and pesticides, nurses can visit the socio-environmental object, interacting with the worker (subject), the environment (work space) and pesticides (work tool). We conclude that nurses are fundamental in all areas of health care for rural workers and their families, especially in the promotion and prevention of diseases caused by the use of agrochemicals.
\end{abstract}

Keywords: Nurse; Agrochemical; Environment; Rural worker.

\section{Resumen}

El objetivo es identificar la situación de la enfermedad frente a los trabajadores rurales y el medio ambiente expuesto a los productos agroquímicos entre 2010 y 2020. Se trata de una investigación cualitativa de revisión integradora en 13 artículos encontrados en bases de datos seleccionadas. Hubo 13 artículos que cumplieron los criterios de inclusión. Los resultados indican que los agroquímicos en pequeña o moderada cantidad contaminan el suelo, el agua y los seres vivos, provocando infecciones que deben ser notificadas por los profesionales de la salud al SINAN, ofrece los subsidios de Vigilancia Sanitaria para el cuidado del medio ambiente. Al comprender la relación entre los trabajadores rurales, el medio ambiente y los plaguicidas, las enfermeras pueden visitar el objeto socio-ambiental, interactuando

\footnotetext{
${ }^{1}$ Enfermeira. Secretaria de Estado da Saúde de Santa Catarina. E-mail mcatarinarosagmail.com https://orcid.orgg/0000-0003-0702-1640

${ }^{2}$ Enfermeira. Autônoma. E-mail juliana_berns15@hotmail.com https://orcid.org/0000-0003-4569-4598

${ }^{3}$ Enfermeira. Secretaria de Estado da Saúde de Santa Catarina. E-mail grasi_fabio@hotmail.com https://orcid.org/0000-0002-2256-9957
} 
con el trabajador (sujeto), el medio ambiente (espacio de trabajo) y los plaguicidas (herramienta de trabajo). Concluimos que las enfermeras son fundamentales en todas las áreas de atención a la salud de los trabajadores rurales y sus familias, especialmente en la promoción y prevención de enfermedades causadas por el uso de agroquímicos.

Palabras clave: Enfermera; Productos agroquímicos; Medio ambiente; Trabajador rural.

\section{Introdução}

Um dos maiores avanços na produção de alimentos e no controle das pragas, doenças e ervas daninha foi à descoberta dos pesticidas, defensivos agrícolas ou agrotóxicos. O termo "substância organossintéticas" começou a ser utilizado em 1948, a partir do descobrimento da substância Dicloro-Difenil-Ticoroetano (DDT) pelo químico suíço Paul Müller. (Rembischevcki \& Caldas, 2018). Todos os benefícios trazidos com a utilização dos produtos no setor econômico, os agrotóxicos trouxeram malefícios ao meio ambiente e à saúde dos trabalhadores rurais que não conheciam os perigos do manuseio inadequado das substâncias. (Instituto Nacional do Câncer [INCA], 2021)

No Brasil, as substâncias utilizadas no controle das pragas no campo foram nomeadas e regulamentadas como “agrotóxico" através da Lei no 7.802/1989. A terminação utilizada busca denominar todo e qualquer veneno utilizado no setor agrícola, que acarretam danos à saúde humana e ao meio ambiente, devido alguns fatores como: o difícil acesso as informações sobre os produtos por parte dos usuários, baixo nível de escolaridade dos trabalhadores rurais, o uso inadequado de Equipamento de Proteção Individual (EPI), o aumento da produtividade com o uso dos agroquímicos e a redução de perdas nas safras agrícolas. (Rembischevcki \& Caldas, 2018; Valadares; Alves \& Galiza, 2020).

A China é o maior consumidor de agrotóxicos utiliza 1,8 milhão de toneladas ao ano, em segundo lugar está o Brasil e em terceiro lugar os EUA. Em 2017, quando se calcula por venda, o Brasil consumiu 550 milhões de toneladas do produto, o país possui apenas $18 \%$ do seu território como área agricultável, uma agricultura altamente técnica e automizada que utiliza somente 7,6\% desse território. (Rembischevski \& Caldas, 2018; INCA, 2021).

Em 1999, o Brasil utilizou 0,13 milhão de ton./ano e em 2015 0,4 milhão de ton./ano, os dados descrevem o crescimento da utilização do produto no setor agrícola e agropecuário. Em contrapartida o número de postos de trabalho no campo vem decrescendo, sendo em 1995 cerca de 17,9 milhões e em 2006 para 13,9 milhões de trabalhadores rurais nos campos brasileiros. (Rembischevski \& Caldas, 2018).

O Ministério da Saúde disponibiliza no Sistema de Informação de Agravos de Notificações (SINAN) o número de casos de intoxicação por agrotóxicos. Em 2007 foram 2,2 mil casos/ano e em 2017 foram 5,1 mil casos/ano uma escala ascendente no número de casos de intoxicação, apesar do decréscimo no número de postos de trabalho no campo. Em 88\% dos casos as notificações foram por intoxicação aguda e em $42 \%$ a exposição foi ocupacional, entretanto acredita-se que haja subnotificação de casos de intoxicações agudas. O autoenvenenamento por agrotóxico no mundo representa 110 mil a 168 mil (14 a 20\%) das mortes, no Brasil é a segunda escolha para a causa dos suicídios. (Rembischevski \& Caldas, 2018; Ministério da Saúde [MS], 2018; Valadares; Alves \& Galiza, 2020).

A Enfermagem pode atuar diretamente a fim de disseminar medidas de promoção da saúde entre os agricultores e suas famílias, assim como a parcela da população que é atingida direta ou indiretamente por esses agentes nocivos.

Diante da narrativa acima, o artigo tem como objetivo identificar a atuação da Enfermagem frente aos trabalhadores rurais e o meio ambiente exposto aos agrotóxicos entre 2010 e 2020.

\section{Metodologia}

Trata-se de uma pesquisa qualitativa, de revisão integrativa da literatura. Revisão integrativa é uma ferramenta que promove a combinação entre dados da literatura empírica com a teoria qualitativa, permitindo ao pesquisador construir 
conceitos, levantar falhas na área de estudo, revisitar teorias e análise metodológica dos estudos encontrados sobre o tema de pesquisa. (Galvao \& Ricarte, 2019).

Utilizou-se o método e as etapas de pesquisa elencadas por Ganong (1987): a) delimitação da pergunta do estudo; b) escolhas dos critérios de inclusão e exclusão na amostra de pesquisa; c) levantamento e coleta de dados; d) análise dos dados coletados; e) apresentação dos resultados da revisão.

Estruturou-se assim, o Protocolo de Pesquisa desenvolvido nas seis etapas propostas por Ganong (1987). Nesse contexto, configura-se identificar a seguinte pergunta norteadora: Qual o papel desempenhado pela Enfermagem frente aos agricultores e ao meio ambiente expostos aos agrotóxicos no período entre 2010 e 2020 ?

Os critérios de inclusão elencados foram: a) artigos publicados na íntegra, com filtro no idioma português, disponibilizados nas bases de dados pré-selecionadas na Biblioteca Virtual de Saúde (BVS), em bases eletrônicas de dados Scientific Eletronic Library Online (SciELO), Literatura Latino-Americana e do Caribe em Ciências da Saúde (LILACS) e Biblioteca Regional de Medicina (BIREME); b) artigos publicados entre 2010 e 2020; c) com a estratégia de busca: ((enfermagem) AND (enfermeiro) AND (agroquímico)); ((enfermagem) AND (enfermeiro) AND (agrotóxicos)); ((enfermagem) AND (enfermeiro) AND (pesticidas)), apresentadas em títulos, resumos e/ou descritores dos artigos. Critérios de exclusão - todas as publicações que não atendem aos critérios de inclusão delimitados. Foram excluídos da pesquisa: artigos repetidos e incoerentes com a temática em questão, além dos que não atendiam aos critérios de inclusão.

O levantamento dos dados foi realizado nos meses de março e abril de 2021. Na busca inicial foram encontradas 278 publicações nas bases de dados. Após o levantamento das publicações, os títulos e os resumos foram lidos e analisados, segundo os critérios de inclusão e exclusão estabelecidos. Foram eliminadas 275 publicações que não atendiam aos critérios de inclusão. Portanto, 13 artigos atendiam aos critérios de inclusão estabelecidos.

Foram coletados os seguintes dados: título do artigo, autor(es), ano de publicação, periódico de publicação, objetivos e resultados de cada estudo. Os dados coletados foram anotados em planilha do programa Microsoft Excel 2010.

A análise de dados ocorreu em abril de 2021, utilizando-se a Análise de Conteúdo de Minayo (2010), que resultou em duas categorias: Os efeitos dos agrotóxicos ao meio ambiente e ao trabalhador rural; Enfermagem, trabalhador rural e o uso dos agrotóxicos

\section{Resultados}

Os resultados estão apresentados de forma descritiva, possibilitando ao profissional de enfermagem e da saúde, acesso crescente, as publicações relacionadas ao uso dos agrotóxicos na saúde do trabalhador rural e os malefícios ao meio ambiente. No Quadro 1, se apresenta os 10 artigos e as variáveis coletadas para análise. 
Quadro 1 - Artigos científicos em bases de dados eletrônicas, 2010-2020. Florianópolis, 2021.

\begin{tabular}{|c|c|c|c|c|}
\hline $\begin{array}{c}\text { TÍTULO/ } \\
\text { REFERÊNCIA }\end{array}$ & $\begin{array}{c}\text { ANO/ } \\
\text { PERIÓDICO }\end{array}$ & OBJETIVOS & DELINEAMENTO & RESULTADOS \\
\hline $\begin{array}{l}\text { Abordagem } \\
\text { socioambiental na } \\
\text { enfermagem: } \\
\text { focalizando o trabalho } \\
\text { rural e uso de } \\
\text { agrotóxicos }\end{array}$ & $\begin{array}{l}\text { 2016/ } \\
\text { Rev. Bras. } \\
\text { Enferm. }\end{array}$ & $\begin{array}{l}\text { Aplicar uma abordagem } \\
\text { socioambiental na } \\
\text { relação entre saúde } \\
\text { humana e trabalho rural } \\
\text { por meio da verificação } \\
\text { de nexo/associação } \\
\text { entre distúrbios de saúde } \\
\text { e uso de agrotóxicos. }\end{array}$ & $\begin{array}{l}\text { Pesquisa } \\
\text { quantitativa, } \\
\text { transversal, } \\
\text { observacional, } \\
\text { exploratória, com } \\
\text { 331agricultores. }\end{array}$ & $\begin{array}{l}\text { Distúrbios de saúde referidos: } \\
\text { distúrbios mentais }(62,2 \%) \text {, } \\
\text { circulatórios }(49,8 \%) \text {, dermatológicos } \\
(45 \%) \text {, respiratórios }(41 \%) \text { e gástricos } \\
(36,2 \%) \text {. Trabalhadores apresentam } \\
\text { prevalência } 90 \% \text { maior de alterações } \\
\text { dermatológicas. }\end{array}$ \\
\hline $\begin{array}{l}\text { Percepções de } \\
\text { agricultores sobre o } \\
\text { impacto dos agrotóxicos } \\
\text { para a saúde e o meio } \\
\text { ambiente }\end{array}$ & $\begin{array}{l}\text { 2016/ } \\
\text { RECOM }\end{array}$ & $\begin{array}{l}\text { Conhecer a percepção } \\
\text { de trabalhadores rurais } \\
\text { portadores de neoplasia } \\
\text { sobre as implicações do } \\
\text { uso de agrotóxicos. }\end{array}$ & $\begin{array}{l}\text { Pesquisa qualitativa, } \\
\text { com } 13 \\
\text { trabalhadores rurais. }\end{array}$ & $\begin{array}{l}\text { Trabalhadores rurais conhecem os } \\
\text { riscos advindos do uso de agrotóxicos, } \\
\text { os classificam como necessários para } \\
\text { manter a produtividade na agricultura. } \\
\text { Têm noção dos riscos do uso de } \\
\text { agrotóxicos para saúde, o meio } \\
\text { ambiente e os consumidores. }\end{array}$ \\
\hline $\begin{array}{l}\text { Fatores que influenciam } \\
\text { na prevenção de agravos } \\
\text { frente ao uso de } \\
\text { agrotóxicos na ativida } \\
\text { rural: } \\
\text { revisão integrativa }\end{array}$ & $\begin{array}{l}\text { 2016/ } \\
\text { Saúde (Santa } \\
\text { Maria) }\end{array}$ & $\begin{array}{l}\text { Avaliar, na literatura, } \\
\text { fatores que influenciam } \\
\text { na prevenção de agravos } \\
\text { frente ao uso dos } \\
\text { agrotóxicos na atividade } \\
\text { rural. }\end{array}$ & $\begin{array}{l}\text { Pesquisa qualitativa, } \\
\text { de revisão de } \\
\text { literatura. }\end{array}$ & $\begin{array}{l}\text { O não uso de Equipamentos de } \\
\text { Proteção Individual (EPI's), } \\
\text { desconhecimento dos riscos no uso } \\
\text { desses produtos e carência de políticas } \\
\text { governamentais relativas ao tema. }\end{array}$ \\
\hline $\begin{array}{l}\text { Atuação dos } \\
\text { profissionais de saúde } \\
\text { da família frente ao } \\
\text { trabalhador rural } \\
\text { exposto a agrotóxicos }\end{array}$ & $\begin{array}{l}\text { 2017/ } \\
\text { Cienc Cuid } \\
\text { Saude }\end{array}$ & $\begin{array}{l}\text { Conhecer a atuação dos } \\
\text { profissionais de } \\
\text { Estratégia Saúde da } \\
\text { Família frente ao } \\
\text { trabalhador rural } \\
\text { exposto aos agrotóxicos. }\end{array}$ & $\begin{array}{l}\text { Pesquisa qualitativa, } \\
\text { com realização de } \\
15 \text { com profissionais } \\
\text { da saúde. }\end{array}$ & $\begin{array}{l}\text { A atuação dos profissionais se } \\
\text { restringe ao atendimento de } \\
\text { problemas agudos, curativista, para } \\
\text { alívio de sinais e sintomas de } \\
\text { intoxicação. No preventivo, não há } \\
\text { fluxo de atendimento, sem ações } \\
\text { planejadas à educação em relação à } \\
\text { exposição aos agrotóxicos. }\end{array}$ \\
\hline $\begin{array}{l}\text { O uso de agrotóxicos e a } \\
\text { saúde do trabalhador } \\
\text { rural no Brasil }\end{array}$ & $\begin{array}{l}\text { 2018/ } \\
\text { ARIGÓ - Revista } \\
\text { do Grupo } \\
\text { PET e } \\
\text { Acadêmicos de } \\
\text { Geografia da Ufac }\end{array}$ & $\begin{array}{l}\text { Identificar a partir de } \\
\text { uma revisão da literatura } \\
\text { quais os principais } \\
\text { agravos à saúde dos } \\
\text { trabalhadores rurais } \\
\text { que utilizam agrotóxicos } \\
\text { na produção agrícola }\end{array}$ & $\begin{array}{l}\text { Pesquisa qualitativa, } \\
\text { de revisão de } \\
\text { literatura. }\end{array}$ & $\begin{array}{l}\text { O Sistema Integrado de Informação } \\
\text { Tóxico Farmacológico (SINITOX) } \\
\text { em } 2016 \text { foram registrou } 2198 \text { casos } \\
\text { de Intoxicação por Agrotóxico, } 648 \\
\text { por intoxicação ocupacional, } \\
\text { notificados nas regiões Nordeste, } \\
\text { Sudeste e Centro Oeste, representando } \\
29,48 \% \text { casos. }\end{array}$ \\
\hline $\begin{array}{l}\text { O papel da enfermagem } \\
\text { do trabalho na } \\
\text { prevenção de riscos dos } \\
\text { trabalhadores expostos } \\
\text { aos agrotóxicos: uma } \\
\text { revisão bibliográfica }\end{array}$ & $\begin{array}{l}\text { 2019/ } \\
\text { Res. } \\
\text { Soc. Dev. }\end{array}$ & $\begin{array}{l}\text { Estabelecer os } \\
\text { principais aspectos da } \\
\text { exposição do } \\
\text { trabalhador aos agentes } \\
\text { químicos e definir a } \\
\text { relação com os riscos } \\
\text { capazes de tornar } \\
\text { instáveis a sua saúde e } \\
\text { qualidade de vida. }\end{array}$ & $\begin{array}{l}\text { Pesquisa qualitativa, } \\
\text { de revisão de } \\
\text { literatura. }\end{array}$ & $\begin{array}{l}\text { As ações de enfermagem na } \\
\text { conscientização dos participantes, as } \\
\text { ações para manter as condições } \\
\text { psicológicas e físicas, a participação } \\
\text { dos estados e órgãos na formulação de } \\
\text { propostas preventivas, a relevância de } \\
\text { equipamentos de proteção para } \\
\text { eliminar riscos e reforçar a segurança } \\
\text { do trabalhador, são pontos fortes e } \\
\text { positivos para prevenção do risco aos } \\
\text { trabalhadores. }\end{array}$ \\
\hline $\begin{array}{l}\text { O impacto do uso dos } \\
\text { agrotóxicos na saúde } \\
\text { pública: revisão de } \\
\text { literatura }\end{array}$ & $\begin{array}{l}2020 / \\
\text { Revista } \\
\text { Saúde e } \\
\text { Desenvolvimento } \\
\text { Humano }\end{array}$ & $\begin{array}{l}\text { Identificar a produção } \\
\text { teórica referente aos } \\
\text { impactos dos } \\
\text { agrotóxicos na saúde } \\
\text { pública }\end{array}$ & $\begin{array}{l}\text { Pesquisa qualitativa, } \\
\text { de revisão de } \\
\text { literatura. }\end{array}$ & $\begin{array}{l}\text { As regiões com uso de agrotóxicos em } \\
\text { larga escala a população apresentou } \\
\text { maiores taxas de alterações auditivas, } \\
\text { problemas gestacionais, doenças } \\
\text { neurológicas, neoplasias e } \\
\text { intoxicações agudas. Problemas } \\
\text { ambientais como detrimento dos } \\
\text { recursos hídricos para consumo } \\
\text { humano e contaminação das águas. }\end{array}$ \\
\hline
\end{tabular}




\begin{tabular}{|c|c|c|c|c|}
\hline $\begin{array}{l}\text { trabalhadores rurais que } \\
\text { fazem uso de agrotóxico } \\
\text { na colheita de acerola } \\
\text { no povoado Jenipapo, } \\
\text { Lagarto/SE }\end{array}$ & & $\begin{array}{l}\text { no processo de trabalho } \\
\text { em coletores de acerola } \\
\text { do povoado Jenipapo de } \\
\text { Lagarto/SE. }\end{array}$ & literatura. & $\begin{array}{l}\text { e } 68 \text { anos de idade, }(27 \%) \text { casados, } \\
\text { amasiados ou solteiros, } 15 \% \\
\text { separados ou divorciados. } 63 \% \\
\text { trabalham de } 8 \text { a } 10 \text { horas no campo } \\
\text { enquanto } 38 \% \text { trabalham de } 6 \text { a } 8 \\
\text { horas na agricultura. O estado de } \\
\text { saúde, dizem } 42 \% \text { regular, } 23 \% \text { ótimo } \\
\text { e } 19 \% \text { bom. }\end{array}$ \\
\hline $\begin{array}{l}\text { Fatores relacionados à } \\
\text { saúde ocupacional de } \\
\text { agricultores expostos a } \\
\text { agrotóxico }\end{array}$ & $\begin{array}{l}\text { 2020/ } \\
\text { Saúde Soc. } \\
\text { São Paulo }\end{array}$ & $\begin{array}{l}\text { Analisar se } \\
\text { características } \\
\text { sociodemográficas, } \\
\text { capacitação técnica e } \\
\text { percepção de risco estão } \\
\text { relacionados com a } \\
\text { saúde ocupacional de } \\
\text { agricultores expostos a } \\
\text { agrotóxicos, no } \\
\text { município de Cerro } \\
\text { Largo, RS. }\end{array}$ & $\begin{array}{l}\text { Pesquisa qualitativa, } \\
\text { transversal, } \\
\text { observacional, com } \\
\text { realização de } 113 \\
\text { entrevistas com } \\
\text { agricultores. }\end{array}$ & $\begin{array}{l}\text { Prevalência do sexo masculino, baixo } \\
\text { nível de escolaridade, idade entre } 51 \mathrm{e} \\
76 \text { anos, trabalham em pequenas } \\
\text { propriedades rurais. A maioria dos } \\
\text { agricultores afirma ter recebido } \\
\text { treinamento para uso de agrotóxicos } \\
\text { por empresas. Os agricultores } \\
\text { reconhecem os riscos da exposição } \\
\text { ocupacional a agrotóxicos e relatam } \\
\text { sintomas de intoxicação. Observa-se a } \\
\text { não existência de orientações pelos } \\
\text { órgão municipais, apresar das queixas } \\
\text { de sintomas de intoxicação por } \\
\text { agrotóxicos. }\end{array}$ \\
\hline $\begin{array}{l}\text { Notificação de } \\
\text { intoxicação por } \\
\text { agrotóxicos: desafios para } \\
\text { a enfermagem no oeste } \\
\text { do Paraná }\end{array}$ & $\begin{array}{l}\text { Faz Ciência/ } \\
2020\end{array}$ & $\begin{array}{l}\text { Fazer o levantamento de } \\
\text { informações para } \\
\text { verificar dados sobre o } \\
\text { Sistema de Informação } \\
\text { de Agravos de } \\
\text { Notificação (SINAN), } \\
\text { Intoxicação } \\
\text { Exógena/Agrotóxicos } \\
\text { nas Unidades Básicas de } \\
\text { Saúde e Unidades de } \\
\text { Pronto Atendimento da } \\
20^{a} \text { regional da Saúde } \\
\text { de Toledo - PR }\end{array}$ & $\begin{array}{l}\text { Pesquisa qualitativa } \\
\text { de questionário on- } \\
\text { line com } 36 \\
\text { questionários } \\
\text { recebidos dos } 119 \\
\text { enviados aos } \\
\text { enfermeiros da } \\
\text { regional de saúde. }\end{array}$ & $\begin{array}{l}\text { Percebe-se a existência de prováveis } \\
\text { subnotificações de intoxicações por } \\
\text { parte da equipe de saúde. Necessidade } \\
\text { de atualizar os profissionais em } \\
\text { relação ao correto preenchimento e } \\
\text { conhecimento dos agravos em saúde } \\
\text { relacionados aos agrotóxicos. }\end{array}$ \\
\hline $\begin{array}{l}\text { Percepção de uma } \\
\text { população rural sobre o } \\
\text { uso de } \\
\text { Agrotóxicos }\end{array}$ & $\begin{array}{l}\text { 2021/ } \\
\text { Pesq. cuid. } \\
\text { fundam. online }\end{array}$ & $\begin{array}{l}\text { Identificar o } \\
\text { conhecimento de uma } \\
\text { população rural sobre as } \\
\text { implicações na saúde } \\
\text { geradas pelo uso } \\
\text { abusivo de agrotóxicos. }\end{array}$ & $\begin{array}{l}\text { Pesquisa qualitativa } \\
\text { descritiva, } \\
\text { exploratória com } 13 \\
\text { agricultores. }\end{array}$ & $\begin{array}{l}\text { Os participantes conhecem o conceito } \\
\text { de agrotóxicos, contudo, apresentam } \\
\text { falha na identificação dos prejuízos } \\
\text { gerados à saúde. Outro fator } \\
\text { destacado é o desuso dos } \\
\text { equipamentos de proteção individual, } \\
\text { da mesma forma, que o } \\
\text { desconhecimento das possíveis } \\
\text { atividades promotoras da saúde. }\end{array}$ \\
\hline
\end{tabular}

Fonte: Bases eletrônicas de dados SciELO, LILACS e BIREME. Abril (2021).

\section{Discussão}

A concentração de publicações foi em 2020 com 5(38,4\%) estudos, 2016 com 3(23\%) estudos, seguido por 1(7,7\%) 2017, 1(7,7\%) estudo em 2018, 1(7,7\%) estudo em 2019 e 1(7,7\%) estudo em 2021 respectivamente. A pesquisa qualitativa a escolha em 11(46,1\%) publicações pelos pesquisadores.

\section{Os efeitos dos agrotóxicos ao meio ambiente e ao trabalhador rural}

A interação do enfermeiro com o ambiente de trabalho rural abre espaço para a construção de conhecimento teórico, prático e metodológico na Enfermagem, no ambiente sócio ambiental do trabalhador rural e sua relação com o processo produtivo, no uso de agrotóxicos e no processo saúde/doença. (Viero et al. 2016).

No estudo de Miorin et al. (2016), as pesquisadoras entrevistam 13 agricultores que utilizam agrotóxicos durante o plantio dos hortifrutigranjeiros. Os entrevistados relatam a necessidade do uso de agrotóxicos para as plantas cresçam, 
entretanto reconhecem que os agrotóxicos agridem o meio ambiente. No trabalho rural, o agricultor e o meio ambiente interagem construindo um resultado em comum: a produção. Entretanto, se o agricultor utilizar agrotóxico, de forma inadequada no processo e no local de trabalho, o ambiente, o trabalhador e a própria produção se contaminam.

Os riscos não aumentam somente quantitativamente, mas também surge qualitativamente, como a poluição do ar, da água, dos alimentos provenientes do uso inadequado dos agrotóxicos. Portanto, todos estão inevitavelmente interligados e expostos aos agrotóxicos, seja na produção dos alimentos, na contaminação ambiental e/o na contaminação ocupacional. O resultado é a degradação da natureza, desiquilíbrio da fauna e flora, destruição da mata ciliar, desvios e destruição de rios e mananciais de água potáveis. (Machado et al., 2017).

Para Viero et al. (2016), o uso dos agrotóxicos sem monitoramento adequado no meio ambiente é resultado da sociedade moderna, busca a produtividade, entretanto esta situação potencial de risco infere negativamente no direito a saúde dos homens e na preservação do meio ambiente. Para atender a qualidade dos alimentos oriundos do campo, em 2001 a Agência Nacional de Vigilância Sanitária (ANVISA) instituiu o Programa de Análise de Resíduos de Agrotóxicos em Alimentos (PARA). O objetivo do PARA é avaliar continuamente os níveis de resíduos nos alimentos in natura que chegam à mesa do consumidor. (Escola Nacional de Saúde Pública Sérgio Aroucha [ENSP], 2016).

O estudo realizado pelo PARA (2020) analisa 50 alimentos (alimento inteiro e casca) consumidos diariamente pela população brasileira entre cereais, frutas, leguminosas e oleaginosas, raízes, tubérculos e bulbos, hortaliças folhosas e não folhosas e café. O estudo identifica 122 tipos agrotóxicos presentes nas amostras, 49\% das amostras apresenta ausência do produto, em $28 \%$ a presença estava no limite, $23 \%$ com inconformidade, $0,89 \%$ presença com risco agudo e $0 \%$ não foi encontrado risco crônico do uso do produto. Entre os alimentos com presença de resíduos estão laranja, goiaba, uva e abacaxi que apresentam risco agudo. (Agência Nacional de Vigilância Sanitária [ANVISA], 2020). No estudo anterior realizado pelo PARA (2016) o potencial risco agudo para agrotóxico se apresenta em 14 alimentos analisados inteiros e casca, os cinco primeiros foram laranja abacaxi, couve, uva e alface. Apesar da redução do risco de exposição com a eliminação da casca, independente da quantidade utilizada de agrotóxico no meio ambiente, sobretudo nos alimentos, ele sempre será tóxico e existe o risco de contaminação. (ANVISA, 2016).

A Vigilância em Saúde Ambiental (VSA) consiste em um conjunto de ações que proporciona o conhecimento e a detecção de mudanças nos fatores determinantes e condicionantes do meio ambiente que interferem na saúde humana, com a finalidade de identificar as medidas de prevenção e controle dos fatores de risco ambientais relacionados às doenças ou a outros agravos à saúde. A VSA cuida das reservas hídricas, dos riscos ambientais, gerencia os resíduos de serviços de saúde, participa das estratégias de contenção e controle de calamidades e desastres, além de implantar a Vigilância em Saúde de Populações Expostas aos Agrotóxicos. A Secretaria de Vigilância em Saúde (SVS) é responsável pelas ações de vigilância, prevenção e controle de doenças crônicas não transmissíveis, saúde ambiental e do trabalhador. (MS, 2017).

Florence Nightingale, fundadora da Enfermagem moderna, chama atenção para a observação do meio ambiente no seu livro "Notes on Nursing" no alcance do equilíbrio entre saúde e doença, a integração entre meio ambiente e os riscos à saúde ocupacional dos trabalhadores rurais no uso de agrotóxicos devem ser avaliados diariamente pelo enfermeiro. Entretanto, o enfermeiro no cotidiano do seu trabalho assistencial ainda não incorporou o seu papel na saúde ambiental, restringindo-se no atendimento pontual das vítimas dos desmandos e impactos causados pelos agrotóxicos ao meio ambiente. (Ribeiro \& Bertolozzi, 2003; Berrêdo et al., 2018). O papel do enfermeiro na VSA é planejar, organizar, controlar a avaliar ações de promoção em saúde, assim como atuar na epidemiologia, saúde do trabalhador, vigilância ambiental, vigilância sanitária, programa de imunização, combate a dengue, entre outras atividades.

A ausência de políticas públicas no controle da produção, comercialização, técnicas, métodos e substância que comprometa a qualidade de vida e o meio ambiente, na prevenção de agravos relacionados à intoxicação por agrotóxicos 
associado ao não uso de Equipamentos de Proteção Individual (EPI) e a baixa escolaridade dificultam o entendimento das instruções sobre o uso das substâncias, além de causar a cada ano danos à saúde dos trabalhadores rurais e ao meio ambiente, associada à agricultura de produção químico-dependente. O uso excessivo de fertilizantes causa acidificação dos solos e contaminação de reservatórios de água. O investimento na produção limpa e orgânica, o uso de agentes de controle biológico, podem ajudar a diminuir significativamente os danos á saúde do trabalhador rural e ao meio ambiente. (Viero \& Camponagara, 2016; Pereira et al., 2019).

Os agrotóxicos são substâncias com baixa solubilidade em água e alta atividade biológica. A Portaria n 2.914/2011 do Ministério da Saúde define os procedimentos essenciais que garantem a qualidade da água potável e utilizável no consumo humano, assim como o quantitativo aceitável de alguns agrotóxicos utilizados na agricultura. (MS, 2011).

No estudo de Soares Pereira et al. (2017), realizado no município de Campo Novo Parecis no estado de Mato Grosso, os pesquisadores encontram alto uso de agrotóxicos que se enquadram como altamente perigosos e utilizados em grandes áreas utilizadas nas culturas de soja, milho e girassol. As substâncias possuem 26,1\% de componentes ativos listados como de risco para contaminação de águas subterrâneas. A preocupação é com a contaminação do manancial freático e águas subterrâneos, assim como o aumento do uso/descarte das substâncias e embalagens na rede freática. O monitoramento através de exames laboratórios, capacitação dos trabalhadores rurais e o recolhimento adequado das embalagens podem garantir a proteção do solo e da água.

Há carência de efetividade das políticas públicas no interior do território brasileiro. No estudo de Lara et al. (2020) as autoras constatam que no interior dos estados da região Nordeste não são seguidas as regulamentações federal e estadual referente ao uso de agrotóxicos, existe uma deficiência de ações educativas sobre o assunto e o uso de métodos alternativos no controle das pragas para o controle de doenças no ser humano, além de ações eficazes de monitoramento, fiscalização e notificação da vigilância ambiental. Quando analisado o uso do agrotóxico e contaminação em águas superficiais e profundas no estado do Ceará identifica 198 ingredientes ativos em seus mananciais, causa de preocupação com o uso da agua para o consumo humano e o desenfreado avanço do agronegócio.

O estado do Paraná é um dos estados que mais consomem agrotóxicos no sistema agropecuário. Em 2016 dos municípios monitorados pela Vigilância de Populações Expostas aos Agrotóxicos (VSPEA), oito municípios do oeste paranaense apresentam nível alterado de potabilidade da água pela presença de agrotóxicos. A contaminação nos alimentos e na água causa no homem dores de cabeça, fraqueza, mal-estar, dor de estômago e sonolência. O Paraná é um dos maiores usuários de agroquímicos do país. (Hort \& Ahlert,2020).

Os agrotóxicos podem ser bastante persistentes, apresentando meia-vida de décadas, são transportados a longas distâncias, podem atingir águas subterrâneas, rios e solos. As intoxicações agudas e sobreaguda causadas por agrotóxicos, herbicidas, fertilizantes ou agroquímicos, acontecem a partir de pequena ou moderada exposição às substâncias que contaminam o solo a água e os seres vivos. Já a infecção crônica acontece por exposição às substâncias cancerígenas na contaminação de caráter ambiental. O resultado são tumores, má formação, abortos frequentes são doenças e agravos que ocorrem pela exposição aos agroquímicos que irão alterar os sistemas imunológico, neurológico, hematopoiético, respiratório, cardiovascular, geniturinário, gastrointestinal, hepático, reprodutivo e endócrino. (Hort \& Ahlert, 2020).

As intoxicações por agrotóxicos, a partir de 2011, passam a ser considerado pela Portaria nº 104/MS/2011 no Anexo I agravos de notificação compulsória em todos os serviços de saúde. Contudo, os registros oficiais quanto à exposição a agrotóxicos são bastante limitados e, em geral, referem-se apenas às intoxicações agudas por agrotóxicos. Uma iniciativa governamental para resolver o problema é a notificação através do Sistema Nacional de Agravos Notificados (SINAN). (MS, 2011). 
As intoxicações por agrotóxicos pelos trabalhadores rurais é um agravo de notificação ao SINAN, a notificação melhora o conhecimento da morbimortalidade pela Vigilância em Saúde, oferece subsídios para o cuidado ampliado das populações que se expõe aos agrotóxicos, auxilia na busca de abordagens integrativas e interdisciplinares. (Viero et al., 2016).

Os profissionais da saúde, inclusive a área da Enfermagem, devem utilizar a ficha de Intoxicação Exógena Agrotóxicos do Sistema de Agravos de Notificação (SINAN) para notificar casos suspeitos e confirmados de intoxicação atendidos nos ambientes da Atenção Básica (Unidade Básica de Saúde e Pronto Atendimento) e Hospitalar (Ambulatório e Hospital).

\section{A enfermagem frente ao trabalhador rural e aos agroquímicos}

O crescimento populacional mundial exige que os países acelerem a produção agrícola, o investimento em tecnologia produz maquinários e softwares que facilita a vida do homem no campo. Ao mesmo tempo ocorre à impulsão na produção de substâncias agroquímicos, na busca de evitar ao máximo perca nas safras agrícolas. É importante ressaltar, que socialmente, as pessoas não compram alimentos danificados esses recebem o destino do lixo, os alimentos precisam ser bonitos e duráveis para serem levados para casa pelo consumidor final.

Agrotóxicos são compostos químicos utilizados no agronegócio pelos produtores rurais, para eliminar elementos indesejáveis da produção, incluem insetos, roedores, fungos e plantas daninhas. Os produtos são potencialmente tóxicos para o meio ambiente e para outros organismos vivos, inclusive para o ser humano. A interação entre homem/trabalhador e o meio ambiente/ambiente de trabalho compõe os objetos socioambientais, requer compreensão e equilíbrio, entre a produção de alimentos e a saúde do trabalhador. O trabalhador rural para acelerar o processo de produção dos alimentos, utiliza os agrotóxicos do plantio à colheita, seja por desleixo ou descuido, acaba sendo afetado direta ou indiretamente pelos pesticidas, ocasionando as doenças agudas e a cronicidade. (Cesar-Vaz et al., 2016).

A Política Nacional de Atenção Básica (PNAB) através da Portaria de Consolidação no 2, Anexo XXII de 2017, estabelece a revisão da regulamentação de implantação e operacionalização vigente no âmbito do Sistema Único de Saúde (SUS), estabelecendo as diretrizes para a organização do componente da Atenção Básica (AB) na Rede de Atenção à Saúde (RAS). (MS, 2017).

A portaria, conforme normatização vigente no SUS define a organização em RAS como estratégia para o cuidado integral e direciona as necessidades de saúde da população. Considera a pessoa em sua singularidade e inserção sociocultural, buscando produzir a atenção integral, incorporar as ações de vigilância em saúde a qual constitui um processo contínuo e sistemático de coleta, consolidação, análise e disseminação de dados sobre eventos relacionados à saúde, além disso, visa o planejamento e a implementação de ações públicas para a proteção da saúde da população, a prevenção e o controle de riscos, agravos e doenças, bem como a promoção da saúde. (MS, 2014).

A Saúde da Família é a estratégia prioritária para expansão e consolidação da AB, resultado da experiência acumulada por um conjunto de atores envolvidos historicamente com o desenvolvimento e a consolidação do SUS. (Brasil, 2011). O enfermeiro ao compreender a relação entre o trabalhador rural, o meio ambiente e os agrotóxicos, permite-se visitar o objeto socioambiental, ou seja, o enfermeiro interage com o trabalhador (sujeito), o meio ambiente (espaço de trabalho) e os agrotóxicos (ferramenta de trabalho). A aproximação ocasiona impacto na Enfermagem, contribuindo para a construção do conhecimento (produção saúde/doença) e do cuidado as populações rurais doentes. (Cesar-Vaz et al., 2016).

No estudo de Machado et al. (2017) realizado com 15 profissionais da saúde ( 3 enfermeiros, 3 médicos, 3 técnicos de enfermagem e 3 agentes comunitário de saúde) atuantes em três unidades de Estratégia Saúde da Família (ESF) em um município da região Sul, os profissionais reconhecem a preocupação com o adoecimento por câncer dos moradores residentes nos territórios adscrito de sua área de atendimento. As doenças identificadas são o câncer, adoecimento psíquico (depressão e 
suicídio), intoxicações e acidentes de trabalho leves e graves. As pesquisadoras identificam nas falas dos enfermeiros a precariedade nas condições de trabalho que favorece o desencadeamento dos eventos adversos no campo, entretanto nenhuma das três ESF apresenta um plano de ação com os vulneráveis a essas condições. As ESF atendem os mais vulneráveis (idosos, diabéticos, hipertensos...) e a demanda espontânea que busca atendimento nas unidades de saúde (consultas espontâneas, curativos, administração de medicamentos, vacinas, triagem...).

No estudo realizado por Viero et al. (2016) foram entrevistados 15 trabalhadores rurais. Destes, 11 trabalhadores relata usar agrotóxicos a cerca de 30 anos, o que leva as pesquisadoras a levantar que a cronicidade de doenças é resultado da exposição à intoxicação exógena. A pressão exercida pelo mercado consumidor de alimentos ocasiona a falta de perspectiva do trabalho rural sem o uso dos agrotóxicos, minando as opções de escolha de estilo de vida e trabalho.

$\mathrm{Na}$ atual idade contemporânea os processos de trabalho tornam-se cada vez mais perigosos e arriscados, expondo cada vez mais o trabalhador em um processo cada vez mais desenfreado, que acarreta em danos irreversíveis à sua saúde. Cada vez mais se questiona o modelo de vida levando-se em conta, também, as condições laborais a que o trabalhador vivencia todos os dias.

Os profissionais da saúde, inclusive a Enfermagem, aprendem na graduação que toda ação em saúde acontece a partir de um conceito de saúde-doença. As ações têm como objetivo a prevenção de doenças, promoção da saúde e a manutenção do processo de equilíbrio do organismo vivo. No caso do uso incorreto dos agroquímicos pelos trabalhadores rurais, os produtos agem como o desencadeador unicausal biológico de doenças e vários tipos de agravos. (Verdi et al. 2016).

No estudo de Martins et al. (2019), realizado a partir de uma revisão de literatura sobre enfermeiros do trabalho e os agrotóxicos, as autoras apresentam um panorama positivo do papel do profissional, apesar da ressalva realizada sobre a falta de informações sobre mecanismos de utilização dos agroquímicos, ausência de priorização da saúde pública nas áreas de uso e a necessidade de divulgação dos itens de proteção individual no manuseio dos agrotóxicos. O papel do enfermeiro do trabalho é identificar as causas das intoxicações, reduzir sinais e propor ações para garantir as melhores condições de vida para os expostos aos agrotóxicos, reduzir o absentismo por doença, promover melhorias e reformas nos locais de trabalho para um ambiente saudável e produtivo.

Em 1990, o Sistema Único de Saúde (SUS) foi regulamentado pela Lei 8080/90 e a Lei 8142/90, e teve como objetivo principal formular e implementar a política nacional de saúde dedicada a promover condições de vida saudável, prevenir riscos, doenças e agravos à saúde da população e garantir o acesso equitativo ao conjunto dos serviços assistenciais na perspectiva da atenção a saúde de forma integral. (Ministério da Saúde, 1990). Perante o SUS, cita-se a Política Nacional de Segurança e Saúde no Trabalho (PNSST) com objetivos da promoção da saúde e a melhoria da qualidade de vida do trabalhador e a prevenção de acidentes e de danos à saúde advindos, relacionados ao trabalho ou que ocorram no curso dele, por meio da eliminação ou redução dos riscos nos ambientes de trabalho. (Ministério da Previdência Social [MPS], 2004; Presidência da República, 2011).

Os princípios de qualidade e gestão do SUS compreendem integralidade, universalidade, equidade e participação social. A equipe de enfermagem tem aproximação com a população que busca as unidades de saúde, os agentes comunitários conhecem a área adscrita e seus moradores, cabe ao enfermeiro articular as equipes para que ações de prevenção e promoção sejam desenvolvidas. (Hort \& Ahlert, 2020).

O Centro de Referência em Saúde do Trabalhador (CEREST) vem contribuindo para implementar ações na área da saúde física e mental que atendam a conscientização e a orientação sobre equipamentos de segurança. O CEREST é dividido em núcleos regional e estadual, tem como atividades irradiar suporte técnico e científico na saúde do trabalhador em articulação com o SUS, cabendo ao SUS funcionar como porta de entrada e receber o trabalhador no sistema da Atenção Primária. (MS, 2007). 
O núcleo básico do CEREST Regional conta com 8 profissionais, assim distribuído: 2 médicos, 1 enfermeiro especialista em trabalho, 3 profissionais de nível superior (com especialização na área de trabalho), 1 técnico de enfermagem e 1 profissional de nível médio (administrativo ou da área do trabalho). O núcleo básico CEREST Estadual conta com 10 profissionais, assim distribuído: 2 médicos, 1 enfermeiro especialista em trabalho, 5 profissionais de nível superior (com especialização na área de trabalho), 1 técnico de enfermagem e 3 profissionais de nível médio (administrativo ou da área do trabalho). O trabalhador, referendado da Atenção Primária, o CEREST atende os acometidos por doenças e agravos relacionados ao trabalho; promove, protege e recupera o trabalhador; e a partir da notificação do SINAN investiga as condições de trabalho. Os CERESTs visam atender todos os trabalhadores(as) rurais em todas as regiões do país, o número de enfermeiros para cada centro de referência impossibilita ações que atendam os trabalhadores rurais expostos aos agrotóxicos nos locais de trabalho, o atendimento acontece de forma ocasional na estrutura física da instituição. (MS, 2007; Maturino et al., 2018).

Os CERETs e os órgãos municipais devem avaliar a saúde do trabalhador em âmbito municipal; garantir atendimento aos trabalhadores com doenças relacionadas ao trabalho na Atenção Básica concedendo suporte técnico regional e estadual; garantir suporte técnico nas ações em ambientes de trabalho que envolva integração de vigilância municipal e/ou estadual de média e alta complexidade, e estabelecer, implantar e operacionalizar o Plano Estadual de Atenção Integral à Saúde do Trabalhador. (MS, 2007; Maturino et al., 2018).

O SUS e as políticas públicas falham ao não investir em abordagens e ações integradas de saúde, educação e assistência técnica, apesar de estar previsto, especificamente, nas atribuições e ações do CEREST no campo da saúde do trabalhador em todos os níveis de atenção: Vigilância em Saúde, Programa Saúde da Família, Unidades Básicas, Ambulatórios, Prontos-socorros, Hospitais Gerais e Especializados. Infelizmente no Brasil, ocorre o lobby do negócio agropecuário, fortalecido e com influência juntos ao membros do Congresso Nacional, não há interesse em retirar do mercado os agroquímicos altamente nocivos e aumentar a fiscalização e/ou investir na qualidade de vida do trabalhado rural. (Maturino $e t$ al., Rêgo, 2018; Hort \& Ahlert, 2020).

O papel desempenhado pela Enfermagem na Atenção Primária da Saúde e Atenção Básica de Saúde é a articulação de ações, de promoção, proteção, prevenção, recuperação e reabilitação em uma visão de integralidade do trabalhador, família e comunidade. As ações visam investigar o uso dos agrotóxicos, determinar os expostos pelos agroquímicos (trabalhadores, adultos, idosos, adolescentes, gestantes e crianças), acompanhar e cadastrar as áreas de risco (meio ambiente), prestar o cuidado e encaminhar os doentes que necessitem níveis avançados de atendimento. (Verdi et al. 2016).

O estado de Santa Catarina tem a área rural formada por pequenas propriedades, como a cidade de Antônio Carlos que faz parte do "cinturão verde" da área metropolitana da Grande Florianópolis, pequenas cidades que produzem legumes e hortaliças pela agricultura familiar. Richaz et al. (2021) realiza um estudo com 12 trabalhadores rurais na cidade de Antônio Carlos, os agricultores reconhecem o efeito noviço dos agrotóxicos, alguns nunca usam Equipamentos de Proteção Individual (EPI) na aplicação de agrotóxicos e aplicam a menor quantidade possível das substâncias por serem muito caras. Entretanto, após a colheita ao invés de carpir a terra, preferem usar grandes quantidades de veneno para matar as ervas daninhas. As pesquisadoras reconhecem a importância do papel do enfermeiro da ESF e da equipe multiprofissional na promoção e proteção de agravos, expõe o déficit de conhecimento por parte dos trabalhadores rurais sobre o assunto e a necessidade de investimentos governamentais em ações de saúde.

As características rurais de Santa Catarina de pequenas propriedades rurais administradas pelas famílias é a oportunidade perfeita para execução da agricultura verde, utilizando técnicas sustentáveis e ecológicas de plantio sem ou com uso controlado de agrotóxicos, baseado na execução de ações educativas desenvolvidas diretamente no campo promovendo a agroecologia. (Gomes et al., 2018). 
O estudo de Miorin et al. (2016) evidência que os trabalhadores têm a noção sobre o impacto dos agrotóxicos ao meio ambiente, entretanto não creem na eliminação ou substituição dos pesticidas na produção agrícola. Assim, o foco da promoção em saúde é a disseminação das medidas preventivas de doenças e o uso correto de EPI.

A enfermagem que atua nas ESF em áreas rurais vivencia uma realidade diferente das atuantes na área urbana. O enfermeiro necessita mobilizar a equipe multidisciplinar, para esclarecer aos trabalhadores rurais sobre a importância do uso correto do EPI em todas as fases do trabalho agrícola, no uso dos pesticidas e na preservação do meio ambiente. A correta intervenção do enfermeiro na sensibilização dos envolvidos contribui na redução das patologias causadas por intoxicações agudas e crônicas. (Viero et al., 2016). Identificam situações de risco ou perigos no atendimento pelas ESF e no ambiente de trabalho, que possam causar agravos, doenças e/ou incapacidades e mortes aos trabalhadores, com o objetivo de adotar ou recomendar medidas para a promoção da saúde e a prevenção dos riscos. Propicia o conhecimento e a detecção em torno de problemas que afetam a saúde humana, como a qualidade da água, do ar e do solo, esgotamento sanitário, resíduos de serviços de saúde, substâncias químicas, entre outros. (Presidência da República, 2011).

Para Viero et al. (2016) a enfermagem, com destaque o enfermeiro, empossado do conhecimento técnico e da percepção sobre os riscos dos pesticidas, pode auxiliar na elaboração de estratégias de prevenção de agravos a saúde dos trabalhadores rurais e da comunidade. Uma ESF em sintonia com os problemas relacionados à saúde do trabalhador rural e as implicações do uso inadequado dos pesticidas, tem como ferramenta de acesso a estes indivíduos o diálogo, para promover a prevenção de doenças e a promoção da saúde individual, coletiva e ambiental.

Segundo a Portaria no 25, de 29 de dezembro de 1994, a utilização de EPI, deve envolver no mínimo: seleção do EPI adequado tecnicamente ao risco a que o trabalhador está exposto e à atividade exercida, considerando-se a eficiência necessária para o controle da exposição ao risco e o conforto oferecido segundo avaliação do trabalhador usuário; programa de treinamento dos trabalhadores quanto à sua correta utilização e orientação sobre as limitações de proteção que o EPI oferece; estabelecimento de normas ou procedimento para promover o fornecimento, o uso, a guarda, a higienização, a conservação, a manutenção e a reposição do EPI, visando garantir as condições de proteção originalmente estabelecidas; caracterização das funções ou atividades dos trabalhadores, com a respectiva identificação dos EPI's utilizados nos riscos ambientais. (Ministério do Trabalho e Emprego [TEM], 1994).

Quanto ao uso dos EPI, Cezar-Vaz et al. (2016) refere que dos 369 trabalhadores rurais acompanhados em suas atividades laborais pelas pesquisadoras, 62(56,8\%) trabalhadores calçam botas de borracha, 25(22,9\%) calçam luvas impermeáveis, 22(201\%) usam chapéu de palha e 04(3,66\%) aplicam protetor solar na pele. As pesquisadoras ao acompanhar o trabalho no campo constatam que apenas $1(0,9 \%)$ trabalhador utilizando o pulverizador costal por 25 minutos na plantação, vestia roupas de uso diário, botas de borracha e chapéu de palha, sendo que a área pulverizada ficava próxima às residências e outros tipos de plantações. Os agrotóxicos podem causar uma série de efeitos sobre a saúde humana que podem ser divididos em agudos e crônicos. Os efeitos da intoxicação aguda aparecem em algumas horas e em curto período se manifestam com irritação da pele e olhos, coceira, cólicas, vômitos, diarreia, espasmos, dificuldades respiratórias e convulsões. Estes sinais e sintomas são facilmente reconhecidos, o diagnóstico é mais simples de ser estabelecido e o tratamento melhor definido. Na intoxicação crônica o indivíduo é exposto a pequenas quantidades por longos períodos. Nesse caso há "uma infinidade de efeitos" como redução do sistema imunológico, desregulação endócrina e prejuízos ao sistema nervoso central e o câncer.

\section{Considerações Finais}

A utilização de dados disponibilizados em fontes secundários de estudo possibilita conhecer o envolvimento dos enfermeiros frente ao meio ambiente, os trabalhadores rurais expostos aos agrotóxicos. 
Os estudos apresentam o trabalho dos enfermeiros envolvidos na Atenção Básica de Saúde e os enfermeiros especialistas em saúde do trabalho. Os enfermeiros reconhecem o frágil papel das políticas públicas na aplicação de ações de prevenção, promoção e reabilitação dos trabalhadores rurais, consideram importantíssimo o uso dos EPIs nas atividades laborais.

Os pesquisadores identificam que os agricultores têm percepção quanto ao risco ao meio ambiente e exposição ao uso de agrotóxicos, como os produtos são importados buscam utilizar o mínimo do produto nas lavouras, porém não veem outro caminho. Na hora de preparar a terra para o próximo plantio utilizam os pesticidas em grande quantidade, para eliminar ervas daninha em curto espaço de tempo.

Apesar de conhecer os riscos e prejuízos ao solo e ao meio ambiente, a exposição rotineira vem causando impactos de grande proporção, atingindo águas subterrâneas, solos adjacentes, exportando essas micropartículas a longas distancias através do ar, o que leva a um aumento da população exposta a esses agentes nocivos. O trabalhador rural tem ciência que está levando a mesa do consumidor alimentos provenientes dessas substâncias.

As atribuições do Enfermeiro para minimizar os impactos na saúde dos agricultores e ao meio ambiente causados pela exposição ao agrotóxico, envolve ações educativas e a notificação das intoxicações agudas e crônicas. Algumas medidas de educação permanente (orientar e capacitar profissionais de saúde para a intervenção e promoção dos problemas de saúde e meio ambiente relacionado ao uso de agrotóxicos); programar um sistema de vigilância as populações expostas aos agrotóxicos e uso adequado de EPIs; promover debates sobre a coleta seletiva do lixo e para descarte correto das embalagens contaminadas; promover o Programa de Saúde na Escola (PSE) debates para discussão dos problemas para que as crianças tomem consciência sobre o uso perigoso dos agrotóxicos e sejam multiplicadores de cuidados as substâncias.

Sugestões para trabalhos futuros são pertinentes para conhecermos as dificuldades na adoção do uso dos Equipamentos de Proteção Individual (EPI) pelos agricultores e os diferentes modelos de ambiente rural, o uso dos agrotóxicos pelos agricultores e os cuidados adotados em relação ao meio ambiente. Em unidades de saúde da Atenção Básica localizadas em áreas rurais sugerimos estudos que identifiquem as intervenções de promoção e prevenção realizadas pelos profissionais da saúde com agricultores e familiares expostos aos agroquímicos. Os estudos devem avançar para compreendermos a relação homem-meio ambiente-agroquímicos.

Concluímos que o enfermeiro é fundamental em todas as áreas da saúde que vivenciam o atendimento do trabalhador rural e sua família, principalmente na promoção e prevenção de agravos causados pelo uso dos agroquímicos.

\section{Referências}

ANVISA - Agência Nacional de Vigilância Sanitária (BR). (2020). Programa de análise de resíduos de agrotóxicos em alimentos (PARA): Relatório das análises de amostras monitoradas no período 2017-2018. https://www.gov.br/anvisa/pt-br/assuntos/agrotoxicos/programa-de-analise-de-residuos-emalimentos/arquivos/3770json-file-1

ANVISA - Agência Nacional de Vigilância Sanitária (BR). (2016). Programa de análise em resíduos de agrotóxicos em alimentos (PARA): Relatório das análises de amostras monitoradas no período 2013 a 2015. https://www.gov.br/anvisa/pt-br/assuntos/agrotoxicos/programa-de-analise-de-residuos-emalimentos/arquivos/3778json-file-1

Berrêdo, V. C. M., Brito, H.R. S., Bittencourt, R. P., Santos, D. A. S., Silva, M. S. (2018). Percepção de enfermeiros sobre saúde e meio ambiente adquirida na formação acadêmica. Journal Health NPES, 3(2), 476-491.

Cezar-Vaz, M. R., Bonow, C. A., Mello, M. C. V. A. \& Silva, M. R. S. (2016). Abordagem socioambiental na enfermagem: Focalizando o trabalho rural e uso de agrotóxicos. Rev Bras Enferm., 69(6), 1179-1187. www.scielo.br/pdf/reben/v69n6/0034-7167-reben-69-06-1179.pdf

ENSP - Escola Nacional de Saúde Pública Sérgio Aroucha. (2016). Especialistas reforçam: Contaminação dos alimentos por agrotóxicos é altíssima no Brasil. http://informe.ensp.fiocruz.br/noticias/39807\#: :text=\%E2\%80\%9C70\%25\%20alimentos\%20consumidos\%20in\%20natura,autorizadas\%E2\%80\%9 D\% 2C\%20apontou\%20o\%20produtor

Galvão, M. C. B. \& Ricarte, I. L. M. (2019). Revisão sistemática da literatura: conceituação, produção e publicação. LOGEION: Filosofia da informação, 6(1), 57-73. https://sites.usp.br/dms/wp-content/uploads/sites/575/2019/12/Revis\%C3\%A3o-Sistem\%C3\%A1tica-de-Literatura.pdf

Ganong, L. H. (1987). Integrative Reviews of Nursing. Rev Nurs Health., 10(1), 1-11. https://pubmed.ncbi.nlm.nih.gov/3644366/ 
Gomes, A. C . S., Moraes, L. G. S. \& Moraes, C. R. S. (2018). O uso de agrotóxicos e a saúde do trabalhador rural no Brasil. ARIGÓ - Revista do Grupo PET e Acadêmicos de Geografia da Ufac, 1(1), 53-61. https://periodicos.ufac.br/index.php/arigoufac/article/view/2066

Hort, J. V. \& Ahlert, A. (2020). Notificação de intoxicação por agrotóxicos: desafios para a enfermagem no oeste do Paraná. Faz Ciência, 22(35), 65-81. Disponível em: https://saber.unioeste.br/index.php/fazciencia/article/view/23970/16326

INCA - Instituto Nacional do Câncer José Alencar Gomes da Silva (BR). (2021). Diretrizes para a vigilância do câncer relacionado ao trabalho. https://www.inca.gov.br/en/node/1909

Lara, T. I. C. \& Garcia, S. D. (2020). O impacto do uso dos agrotóxicos na saúde pública: revisão de literatura. Revista Saude e Desenvolvimento Humano, 8(1), 85-96. https://revistas.unilasalle.edu.br/index.php/saude_desenvolvimento/article/view/6087/pdf

Machado, L. M.; Beck, C. L. C.; Coelho, A.P. F.; Weiller, T. H. \& Camponogara, S. (2017). Atuação dos profissionais de saúde da família frente ao trabalhador rural exposto a agrotóxicos. Cienc Cuid Saude, 16(3), 1-8. https://periodicos.uem.br/ojs/index.php/CiencCuidSaude/article/view/37051/pdf

Martins, V. H. S., Carvalho, M. A. B., Belfort, L. R. M., Guisande, T. C. C. A. \& Santos T. V. (2019). O papel da enfermagem do trabalho na prevenção de riscos dos trabalhadores espostos aos agrotóxicos: uma revisão bibliográfica. Res. Soc. Des., 8(6), 1-12. https://www.redalyc.org/journal/5606/560662197019/html/

Marturino, M. M., Fernandes R. C P. \& Rêgo, M. A P. (2018). A atuação do SUS na vigilância de ambientes de trabalho a experiência do Centro Estadual de Referência em Saúde do Trabalhador (CEREST) na Bahia. Rev. Bras Saude Ocup, 43(e 10), 1-13. https://www.scielo.br/j/rbso/a/XkcZxndsXNXLH58wLHgLTZq/?lang=pt\&format=pdf

Minayo, M. C. S. (2010). Pesquisa social: teoria, método e criatividade. (29. ed.). Rio de Janeiro.

MPS - Ministério da Previdência Social (BR). (2004). Política nacional de saúde e segurança do trabalhador. https://www.previdencia.gov.br/arquivos/office/3_081014-105206-701.pdf

MS - Ministério da Saúde (BR). (1990). Lei n ${ }^{\circ}$ 8.080, de 19 de setembro 1990. Dispõe sobre as condições para a promoção, proteção e recuperação da saúde, a organização e o funcionamento dos serviços correspondentes e dá outras providências. https://conselho.saude.gov.br/legislacao/lei8080_190990.htm.

MS - Ministério da Saúde (BR). (2007). Centro de referência do trabalhador - CEREST. https://bvsms.saude.gov.br/centro-de-referencia-em-saude-dotrabalhador-cerest/

MS - Ministério da Saúde (BR). (2011). Portaria $n^{\circ}$ 2.914, de 12 de dezembro de 2011. Dispõe sobre os procedimentos do controle e de vigilância da qualidade da água para consumo humano e seu padrão de potabilidade. https://bvsms.saude.gov.br/bvs/saudelegis/gm/2011/prt2914_12_12_2011.html

MS - Ministério da Saúde (BR). (2011). Portaria $n^{\circ}$ 104, de 25 de janeiro de 2011. Define as terminologias adotadas em legislação nacional, conforme o disposto no Regulamento Sanitário Internacional 2005 (RSI 2005). http://bvsms.saude.gov.br/bvs/saudelegis/gm/2011/prt0104_25_01_2011.html

MS - Ministério da Saúde (BR). (2014). Implantação das Redes de Atenção à Saúde e outras estratégias da SAS. http://bvsms.saude.gov.br/bvs/publicacoes/implantacao_redes_atencao_saude_sas.pdf

MS - Ministério da Saúde (BR). (2017). Portaria de Consolidação $n^{\circ}$ 2, Anexo XXII de 2017. http://bvsms.saude.gov.br/bvs/saudelegis/ gm/2017/MatrizesConsolidacao/Matriz-2-Politicas.html

MS - Ministério da Saúde (BR). (2017). Vigilância em saúde. https://antigo.saude.gov.br/vigilancia-em-saude/vigilancia-ambiental

MS - Ministério da Saúde (BR). (2018). Relatório Nacional de Vigilância em Saúde de Populações Expostas a Agrotóxicos. https://bvsms.saude.gov.br/bvs/publicacoes/relatorio_nacional_vigilancia_populacoes_expostas_agrotoxicos.pdf

MTE - Ministério do Trabalho e Emprego (BR). (1994). Portaria $n^{\circ}$ 25, de 29 de dezembro de 1994. Norma regulamentadora - NR 9. https://www.fenf.unicamp.br/sites/default/files/2018-7/portaria_n_25_29_dez_1994_mt_riscos_ambientais_mapa_de_ris_0.pdf

Miorin, J. D., Camponogara, S., Dias, G. L., Dias, G. L., Silva, N. M. \& Viero, C. M. (2016). Percepções de agricultores sobre o impacto dos agrotóxicos para a saúde e o meio ambiente. R. Enferm. Cent. O. Min., 6(3), 2410-2420. https://www.seer.ufsj.edu.br/index.php/recom/article/viewFile/1117/1173

Pereira, R. A.; Costa, C. M. L. \& Lima, E M. (2019). O impacto dos agrotóxicos sobre a saúde humana e o meio ambiente. Revista Extensão, 3(1), 29-37. https://revista.unitins.br/index.php/extensao/article/view/1684

Presidência da Republica (BR). (2011). Decreto $n^{\circ}$ 7.602, de 7 de novembro de 2011. Dispõe sobre a Politica nacional de segurança e saúde no trabalho PNSST. www.planalto.gov.br/ccivil_03/_ato2011-2014/2011/decreto/d7602.htm

Rembischevski, P. \& Caldas, E. D. (2018). Agroquímicos para controle de pragas no Brasil: análise crítica do uso do termo agrotóxico como ferramenta de comunicação de risco. Vigil. sanit. Debate, 6(4), 2-12. https://visaemdebate.incqs.fiocruz.br/index.php/visaemdebate/article/view/1195

Ribeiro, M. C. S., Bertolozzzi, M. R. (2002). Reflexões sobre a participação da enfermagem nas questões ecológicas. Rev Esc Enferm USP, 36(3), 300-308. http://www.ee.usp.br/reeusp/upload/html/672/body/v36n4a01.htm

Richartz, A.; Heidemann, I. T. S. B.; Vicente, C. (2021). Percepção de uma população rural sobre o uo de agrotóxicos. R. pesq. Cuid. Fundam. Online, 13, 1179-1185. https://www.seer.unirio.br/cuidadofundamental/article/view/9233

Soares, D. F., Faria, A. M. \& Rosa, A. H. (2017). Análise de risco de contaminação de águas subterrâneas por resíduos de agrotóxicos no município de Campo Novo do Parecis (MT), Brasil. Eng Sant Ambient, 22(2), 277-284. https://www.scielo.br/j/esa/a/k65RfZykKnXYkqRbVJvpZSc/?lang=pt\&format=pdf 
Research, Society and Development, v. 10, n. 13, e339101321261, 2021

(CC BY 4.0) | ISSN 2525-3409 | DOI: http://dx.doi.org/10.33448/rsd-v10i13.21261

Valadares, A., Alves, F. \& Galiza, M. (2020). O crescimento do uso de agrotóxicos: uma análise descritiva dos resultados do censo agropecuário de 2017. https://www.ipea.gov.br/portal/images/stories/PDFs/nota_tecnica/200429_nt_disoc_n65.pdf

Verdi, M. I. M., Ros, M. A., Cutolo, L. R., Souza, T. T. (2016). Saúde e Sociedade. https://ares.unasus.gov.br/acervo/html/ARES/7445/1/modulo2saude_e_sociedade-2016.pdf

Viero, C. M. \& Camponogara, S. (2016). Fatores que influenciam na prevenção de agravos frente ao uso de agrotóxicos na atividade rural: revisão integrativa. Saúde, 15-24. https://periodicos.ufsm.br/revistasaude/article/view/12833

Viero, C. M., Camponogara, S., Cezar-Vaz, M. R., Costa, V. Z. \& Beck, C. L. C. (2016). Sociedade de risco: o uso dos agrotóxicos e implicações na saúde do trabalhador rural. Esc Anna Nery, 20(1), 99-105. https://www.scielo.br/j/ean/a/5Fqb6DL4WdCg7dhXfFzNNSR/?lang=pt\&format=pdf 